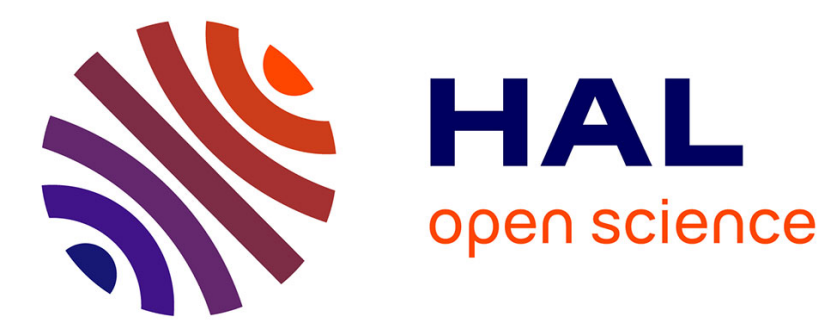

\title{
Streamflow recession analysis using water height
}

Elizabeth Rae Jachens, Clément Roques, D. Rupp, J. Selker

\section{To cite this version:}

Elizabeth Rae Jachens, Clément Roques, D. Rupp, J. Selker. Streamflow recession analysis using water height. Water Resources Research, 2020, 56 (6), 10.1029/2020WR027091 . insu-02874661

\section{HAL Id: insu-02874661 \\ https://hal-insu.archives-ouvertes.fr/insu-02874661}

Submitted on 13 Aug 2021

HAL is a multi-disciplinary open access archive for the deposit and dissemination of scientific research documents, whether they are published or not. The documents may come from teaching and research institutions in France or abroad, or from public or private research centers.
L'archive ouverte pluridisciplinaire HAL, est destinée au dépôt et à la diffusion de documents scientifiques de niveau recherche, publiés ou non, émanant des établissements d'enseignement et de recherche français ou étrangers, des laboratoires publics ou privés.

$$
\text { Copyright }
$$




\section{Water Resources Research}

\author{
RESEARCH ARTICLE \\ 10.1029/2020WR027091 \\ Key Points: \\ - Using water height in place of \\ discharge for recession analysis \\ preserves general characteristics of \\ the recession curve \\ - An analytical expression equating \\ the power law exponents of water \\ height and discharge is given when \\ the rating curve is a power law \\ - The ratio of power law exponents for \\ individual recessions at high and \\ low water heights can identify a \\ transition in streamflow regimes
}

Supporting Information:

- Supporting Information S1

Correspondence to:

E. R. Jachens,

erjachens@gmail.com

Citation:

Jachens, E. R., Roques, C., Rupp, D. E., \& Selker, J. S. (2020). Streamflow

recession analysis using water height.

Water Resources Research, 56,

e2020WR027091. https://doi.org/

10.1029/2020WR027091

Received 9 JAN 2020

Accepted 3 JUN 2020

Accepted article online 8 JUN 2020
(C)2020. American Geophysical Union. All Rights Reserved.

\section{Streamflow Recession Analysis Using Water Height}

\author{
E. R. Jachens ${ }^{1}$ iD, C. Roques ${ }^{2,3}$ (D), D. E. Rupp ${ }^{4}$ iD, and J. S. Selker ${ }^{1}$ iD \\ ${ }^{1}$ Department of Biological and Ecological Engineering, Oregon State University, Corvallis, OR, USA, ${ }^{2}$ Department of \\ Earth Sciences, ETH Zürich, Zurich, Switzerland, ${ }^{3}$ Géosciences Rennes, University of Rennes 1 , Rennes, France, ${ }^{4}$ Oregon \\ Climate Change Research Institute, College of Earth, Oceanic and Atmospheric Sciences, Oregon State University, \\ Corvallis, OR, USA
}

Abstract Recession analysis is widely used for characterizing aquifer and basin properties based on the falling limb of the hydrograph. However, recession analysis using streamflow discharge requires a relationship (the rating curve) between simultaneous measurements of water height, $h$, and discharge, $Q$, across a wide range of flows, which is expensive to obtain, and changes in time. We leverage the relationship between $h$ and $Q$ (typical power law) to perform recession analysis using $h$ directly, thus permitting identification of transient flow regimes, where only $h$ is available. Recession analysis evaluates the rate of change in discharge, $-d Q / d t$, as a function of discharge, $Q$, in a bilogarithmic plot where the slope, $b$, contains information about aquifer characteristics. While values of $b$ are not conserved when replacing $Q$ with $h$, we find that the variability in values of $b$ within and between events is captured in recession analysis for both $Q$ and $h$. For example, when considering individual recessions from a large number of watersheds, a change from a smaller $b$ at high discharge/stage to a larger $b$ at lower discharge/stage occurs in most watersheds and suggests a transition to a more long-lasting, and less drought-sensitive, baseflow regime. With the advent of low-cost reliable pressure loggers, as well as satellites that provide global reporting of river stage, recession analysis using water height expands the number of river systems where recession analysis can be conducted and provides the potential for insights into the variability of watershed drainage characteristics without the need for a discharge record.

\section{Introduction}

The understanding of streamflow dynamics is fundamental for water resources management, flood prediction, sediment transport, and drought assessment. The establishment of accurate hydrographs is critical but is expensive to obtain. Though measuring continuous water height has become easy using automatic pressure transducers, estimating discharge requires a local rating curve constructed from field-collected discharges measurements paired with concurrent water height measurements over the range of flows of interest, typically covering peak to baseflow discharges. These extreme discharges are cause for uncertainties in a rating curve due to their low frequency of occurrence, safety concerns at high discharges, and instrument precision impeding the collection of reliable estimates at low discharges (Kiang et al., 2018). Extrapolation of a rating curve to include extreme events compromises the validity of the hydrograph (Lang et al., 2010). Additionally, a rating curve is no longer valid if the stream undergoes channel changes, a common consequence of high flows (U.S. Department of Agriculture-National Resources Conservation Service (USDA-NRCS), 2012).

The falling limb of a hydrograph is an expression of the processes controlling groundwater discharge to a stream. Recession analysis (RA) employs characteristics of this receding limb to quantify hydraulic properties of the source aquifer. The falling limb of the hydrograph is often described by a power law:

$$
-\frac{d Q}{d t}=a \cdot Q^{b}
$$

where $Q$ is streamflow $\left(\mathrm{m}^{3} / \mathrm{s}\right)$ and $a$ and $b$ are constants (Brutsaert $\&$ Nieber, 1977; Troch et al., 2013). Parameters $a$ and $b$ are often estimated by fitting Equation 1 on recession data in bilogarithmic space, where $\log (a)$ is the intercept and $b$ is the slope (Brutsaert \& Nieber, 1977; Kirchner, 2009; Roques et al., 2017; Rupp \& Selker, 2006a).

Both theory (e.g., Bogaart et al., 2013; Brutsaert \& Nieber, 1977; Rupp \& Selker, 2006b) and observations (e.g., Clark et al., 2009; Mutzner et al., 2013; Rupp \& Selker, 2006a; Tashie et al., 2020) show that the 
parameter $b$ is not typically constant over a recession. Commonly evoked hydraulic theory—relying on analytical solutions to the Boussinesq equation for drainage to a fully penetrating channel from an idealized, initially fully saturated, and unconfined horizontal aquifer-predicts values of $b=3$ for early-time (higher $\underline{Q}$ ) transitioning to $b=1.5$ or 1 for late-time (lower Q) recession (Brutsaert \& Nieber, 1977). However, because of the complexity of natural watersheds, RA performed on streamflow data reveals strong variability in $b$ values beyond the simple bilogarithmically linear representation of Equation 1 for high and low flows (e.g., Biswal \& Marani, 2014; Dralle et al., 2015; McMillan et al., 2011; Mutzner et al., 2013; Ploum et al., 2019; Shaw \& Riha, 2012; Tashie et al., 2019; Wang, 2011). The variability in recession parameters can reveal information about the complexities in watershed response. The shape of the RA plot, which includes any breaks in slope (i.e., changes in $b$ ) as well as other patters that can be identified in individual or collective/cloud of recession events, illustrates the "structural decay of flow."

The parameter $b$ reflects the rate of change in the rate of streamflow recession: A higher value of $b($ for $b>1)$ indicates that the rate of decline decreases more quickly. When considering drought resilience, comparing $b$ values for high and low flows can be used to identify a change in hydraulic regime and using $b$ values at low flows to indicate a watershed's sensitivity to climate change. Where $b$ increases as $Q$ decreases, streamflow becomes more stable, or sustained, at low flows and may indicate watersheds that are less sensitive to drought (Berghuijs et al., 2016; Jachens et al., 2020). In this case, $b$ values are larger at low flows than at high flows. As noted, observations reveal large variability in recession behavior, including cases where $b$ is larger at lower $Q$ than at higher Q (e.g., Clark et al., 2009; Mutzner et al., 2013; Rupp \& Selker, 2006a), inconsistent the aforementioned hydraulic theory. Recent studies have suggested that such cases are common (Jachens et al., 2020; Tashie et al., 2020). In contrast, if $b$ decreases as $Q$ decreases, this indicates that streamflow is more stable, or sustained, at high flows while streamflow declines at a faster rate at low flows. In this case, the smaller $b$ values at low flows could indicate that streamflow in the watershed could be sensitive to drought and vulnerable to climate change. By comparing $b$ values at different ranges of Q (i.e., high and low flows), we can say something about which regime is more sustained and thus the vulnerability to drought. Comparing $b$ at high and low flows, then, may provide a useful metric to characterize watersheds sensitivity to drought.

This paper aims to demonstrate the reliability and utility of performing RA on measured water height recession analysis directly (hereafter referred to as WHRA) in order to estimate the ratio of $b$ from high to low flows and describe the structural decay of streamflow recession without introducing error through the definition and uncertainty of a rating curve. Using WHRA can leverage water height data that are more widely available with the advent of low-cost reliable pressure loggers, as well as satellites that provide global reporting of river stage. We first present the mathematical framework to compare RA and WHRA. We then test the methodology on two real-data watersheds, one with larger $b$ values at high flows compared to low flows and the other with larger $b$ values at low flows compared to high flows. Finally, we test the universality of this methodology on a batch of 37 Swiss watersheds.

\section{Methods}

Here we describe a method for analyzing recession hydrographs using water height instead of discharge rate, leveraging the power law rating curve equation. Rating curves employ a variety of mathematical forms including power law, linear, parabolic, exponential, or a compound segment fit (Kennedy, 1984; Lovellford, 2013).

The power law equation for rating curves is standard (Clarke, 1999; Degagnea et al., 1996; Phillips \& Eaton, 2009; Reitan \& Petersen-Øverleir, 2004) and is consistent with the form of discharge resistance equations such as Manning's and Chezy's (Herschy, 1993; Kennedy, 1984):

$$
Q=c \cdot h^{m}
$$

where $h$ is water height $(\mathrm{m})$ and $c$ and $m$ are constants. The transformation of Equation 1 for WHRA plots substitutes the right-hand side of Equation 2 for discharge, resulting in an expression that is a function of water height: 


$$
\begin{gathered}
\frac{-d Q}{d t}=\frac{-d}{d t}\left(c \cdot h^{m}\right) \\
\frac{-d Q}{d t}=c \cdot m \cdot h^{m-1} \cdot \frac{-d h}{d t}
\end{gathered}
$$

Thus, $-d Q / d t$ versus $Q$ can be expressed in terms of $h$ for the WHRA axes using Equations 2 and 4 as

$$
\left[c \cdot m \cdot h^{m-1} \cdot \frac{-d h}{d t}\right] \text { versus }\left[c \cdot h^{m}\right]
$$

The fitting coefficient $c$ appears on both axes in Equation 5, and thus, the mathematical simplification holds true for bilogarithmic space:

$$
\left[m \cdot h^{m-1} \cdot \frac{-d h}{d t}\right] \text { versus }\left[h^{m}\right]
$$

Equation 6 can be simplified for the special case of $m=1$ and thus $Q=h$ from Equation 1:

$$
\ln \left[\frac{-d h}{d t}\right] \text { versus } \ln [h]
$$

Values of $m$ in the literature for power law rating curves tend to be close to 2 or 3 but can range from 1 to 10 (Fenton \& Keller, 2001; Nathanson et al., 2012; Phillips \& Eaton, 2009; Reitan \& Petersen-Øverleir, 2004, 2008). For simplicity of the calculations, including preserving the axis form from RA, and because no $m$ values are known, the following analysis uses $m=1$. However, we later show that our analysis of the observed streamflow recessions is not very sensitive the assumed value of $m$ and assuming $m=1$ does not affect the results of this analysis or decrease the generality of the results.

The slope of the WHRA plot can be related to the slope of the RA plot by substituting Equations 2 and 4 into the slope calculation as shown in the following equation and simplification:

$$
\begin{gathered}
b_{R A}=\frac{\ln \left(\frac{-d Q_{2}}{d t}\right)-\ln \left(\frac{-d Q_{1}}{d t}\right)}{\ln \left(Q_{2}\right)-\ln \left(Q_{1}\right)}=\frac{\ln \left(c \cdot m \cdot h_{2}{ }^{m-1} \cdot \frac{-d h_{2}}{d t}\right)-\ln \left(c \cdot m \cdot h_{1}{ }^{m-1} \cdot \frac{-d h_{1}}{d t}\right)}{\ln \left(c \cdot h_{2}{ }^{m}\right)-\ln \left(c \cdot h_{1}{ }^{m}\right)} \\
b_{R A}=\frac{m-1+b_{W H R A}}{m}
\end{gathered}
$$

where $b_{\mathrm{RA}}$ is $b$ estimated with RA plot $\ln \left[\frac{-d Q}{d t}\right]$ versus $\ln [Q]$ and $b_{\text {WHRA }}$ is $b$ estimated from WHRA plot $\ln \left[\frac{-d h}{d t}\right]$ versus $\ln [h]$ from Equation 7.

To identify a change in recession behavior between high $(h)$ and low $(l)$ flows, we define the ratio of $b$, $R_{b}=b_{h} / b_{l}$. For a rating curve taking the form of a power law (Equation 2), the ratio of $b$ values during high and low flows, $R_{b}$, is as follows:

$$
R_{b}=\frac{b_{(R A, h)}}{b_{(R A, l)}}=\frac{m-1+b_{W H R A, h}}{m-1+b_{W H R A, l}}
$$

where the subscripts $h$ and $l$ indicate high-flow and low-flow regimes $\backslash$ periods of the recession, respectively.

We classified recessions as either high- or low-flow events based on whether the portion of the recession is greater than or less than the median streamflow of all records. Events that span the median streamflow are classified as high flow events. We calculated a representative value of $R_{b}$ per watershed as the ratio of the median $b_{h}$ to the median $b_{l}$. 
We tested the methodology by first analyzing in detail data from two watersheds from the U.S. Geological Survey (USGS) database for which both water height and discharge measurements were available for at least 10 years: West Conewago Creek near Manchester, PA (USGS Station\# 01574000) and the South Fork of the McKenzie River, OR (USGS Station\# 14159200). West Conewango Creek is located in in the northeastern United States and has a watershed area of $1,321 \mathrm{~km}^{2}$. The South Fork of the McKenzie River is located in the northwestern United States and has a watershed area of $414 \mathrm{~km}^{2}$. We then performed similar analysis on a batch of streamflow time series in order to evaluate the validity of WHRA across different watershed characteristics. For this purpose, we selected watersheds across Switzerland where 30 years of both water height and stream discharge data were freely and readily available (Federal Office for the Environment (FOEN), 2019). We have considered watersheds with limited influence by extended lakes and anthropogenic regulations that could bias the analysis. These leads to the selection of 37 watersheds spanning diverse climate, geomorphological settings and watershed sizes (from 1 to $1,856 \mathrm{~km}^{2}$ ).

For the Swiss watershed data set, daily average discharge data is given in $\mathrm{m}^{3} / \mathrm{s}$ and water height is given in meters above mean sea level. Since there were no published datums or rating curves, we fit power law rating curves, which minimized the root mean square error for water height vs. discharge in log-log space. The optimized datum was subtracted from the watershed's water height data to represent the effective water depth that was used for the final rating curve. The watersheds all have rating curve root-mean-square logarithmic error (RMSLE) below 0.25 [-], which indicates a rating curve without multiple segments that has not changed significantly over time making.

When performing RA, care must be taken when computing the time derivative at low flow to reduce discretization error (Rupp \& Selker, 2006a). Here the exponential time step method was used (Roques et al., 2017). Additionally, mean daily data (discharge or water height) was calculated from the 15 min USGS data to further reduce noise. The beginning of the recession was defined as 1 day after the peak in discharge to exclude the potential influence of overland flow. Based on the uncertainty analysis by Dralle et al. (2017) on recession event selection, we only included recession events with duration $>5$ days of decreasing flow. The end of the recession was defined to be the minimum discharge or height prior to an increase. The sensitivity of recession parameters to the precise hydrograph recession definition was found to be low, consistent with previous studies (Dralle et al., 2017). For the slope of the individual recessions, individual estimates of $a$ and $b$ are based on direct linear fitting using least squares regression in bilogarithms space and the median of all values are used to describe the variation in watershed behavior.

\section{Results and Discussion}

\subsection{Case Study: West Conewago Creek, PA}

West Conewago Creek has published data for discharge and water height starting in October of 2007. The USGS provisional rating curve for West Conewago Creek is best fit by a power law rating curve with $c=16.4\left(\mathrm{~m}^{2} / \mathrm{s}\right)$ and $m=3.4\left(R^{2}=0.96\right)$ based on Equation 2 (USGS, 2018). A total of 244 recession events was identified.

From Figure 1, the similarity of the pattern of points in RA and WHRA plots is evident, demonstrating that the general structural decay of flow is consistently represented in the WHRA and RA methods, though the values of the recession parameters $a$ and $b$ are not. $R_{b}$ is 0.66 based on RA, comparable to the value of 0.60 using WHRA when $m$ is unknown and assumed to be 1 . Notably, $R_{b}$ less than 1 , indicating that the individual recessions at low flow show larger slopes that at high flows (Figure 1). As observed elsewhere (Roques et al., 2017; Tashie et al., 2019), this result is contrary $R_{b}>1$ if the high and low flow $b$ parameters were estimated by first combining all the recession events prior to fitting.

\subsection{Case Study: South Fork of McKenzie River, OR}

The South Fork of the McKenzie River (USGS Station 14159200) has published discharge data beginning in October 2000, although gage height records start in October 2007. The USGS provisional rating curve for the South Fork of the McKenzie River is best fit by a power law rating curve with $c=6.2\left(\mathrm{~m}^{2} / \mathrm{s}\right)$ and $m=2.6$ $\left(R^{2}=0.99\right)$. We analyzed 345 recession events starting in October 2007. Power law (Figure $\left.2 \mathrm{~b}\right)$ water height recession plots show structural decay consistent with the RA plot (Figure 2a), evident by the distinct organization of data points in the lower envelope. RA gives $R_{b}=0.21$ compared to 0.19 using WHRA. As with the 

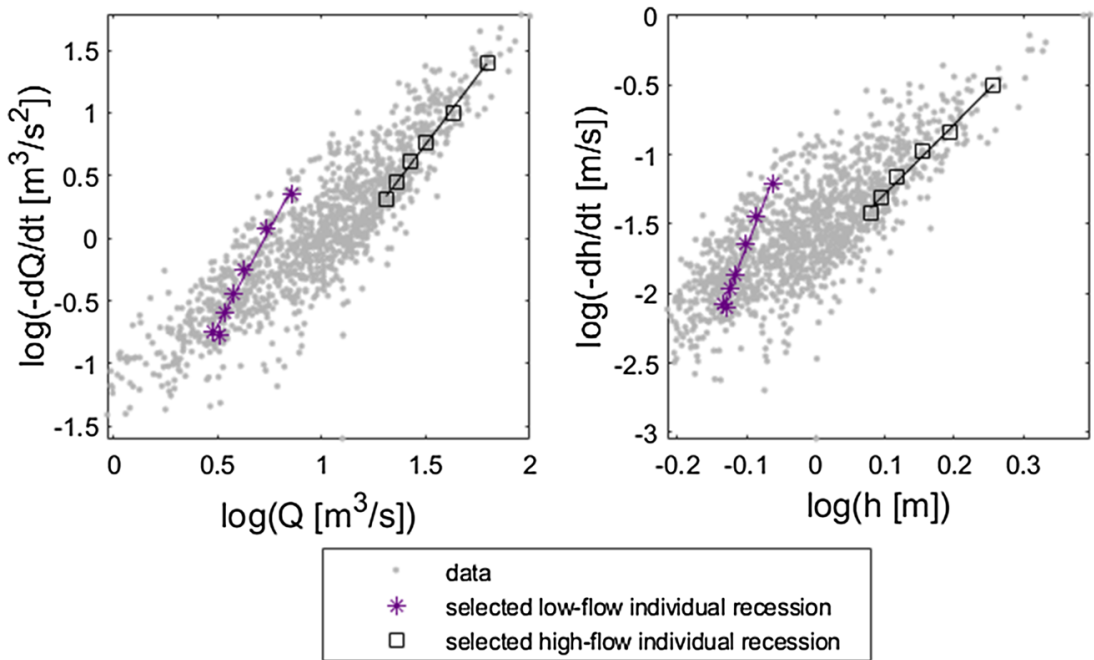

Figure 1. Example individual recessions for high-flow and low-flow for discharge recession analysis (a), and water height recession analysis (b), for West Conewago Creek at USGS Station 01574000. On average, individual recessions at higher ranges of $Q$ or $h$ have smaller slopes that those at lower ranges, resulting in $R_{b}<1$.

previous example (section 3.1), $R_{b}<1$ results from both RA and WHRA using individual recessions (Figure 2).

\subsection{Batch Analysis of Swiss Watersheds}

For the 37 Swiss watersheds, rating curve exponents ranged from $m=1.54-6.11$ with a median of 3.13 and a median RMSLE of 0.09 [-]. The values of $R_{b}$ using WHRA and RA are compared in Figure 3. WHRA generally preserves $R_{b}$ when compared to RA and thus correctly identifies the change in hydraulic behavior without knowing the value of $m$. Only two watersheds are incorrectly characterized using WHRA based on $R_{b}<$ or $<1$, both with $R_{b}<1$ using WHRA but with $R_{b}>1$ using RA. Of the 37 watersheds, 33 watersheds have $R_{b}<1$, indicating that the change in hydraulic behavior is toward a more sustained flow regime (higher $b$ values at late time), contrary to the early to late-time transition to smaller $b$ at low flows predicted by the idealized Boussinesq theory and suggested by many point cloud analyses ( Brutsaert \& Lopez, 1998; Brutsaert \& Nieber, 1977).
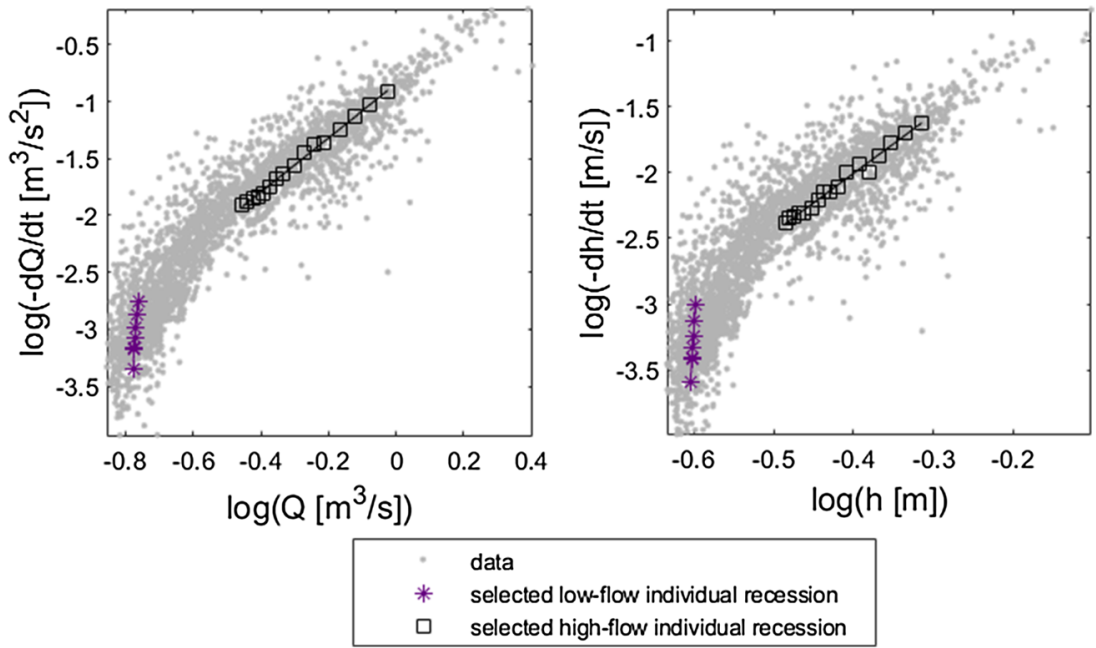

Figure 2. Same as Figure 1 but for the South Fork of the McKenzie River at USGS Station 14159200. 


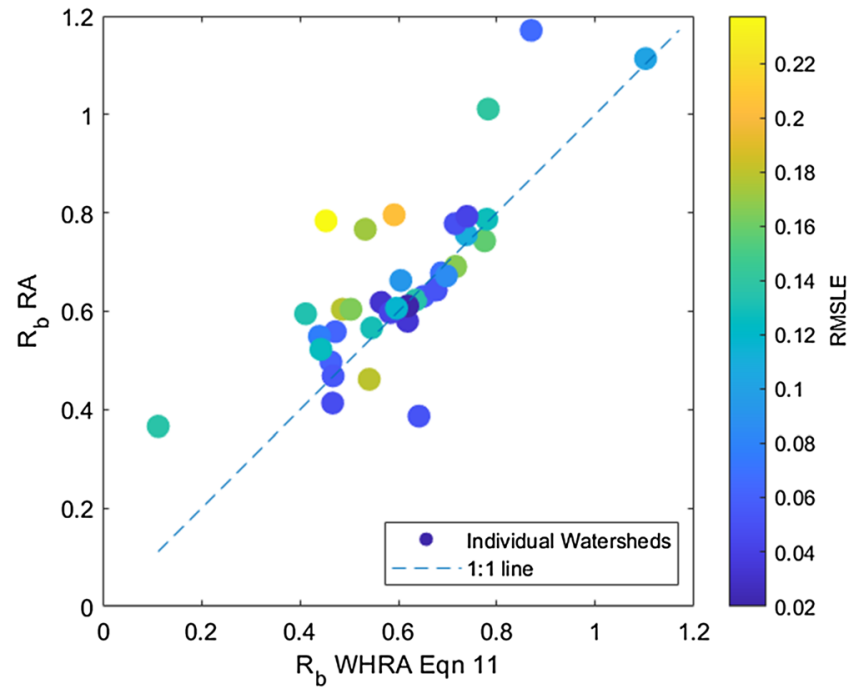

Figure 3. Ratio of high to low median individual slopes $\left(R_{b}\right)$ for WHRA and RA compared to the 1:1 line. The color of the symbol is based on the RMSLE of the power law rating curve as fit in log-log space. The two watersheds are incorrectly characterized using WHRA can be identified in the upper right of the plot both where $R_{b}<1$ using WHRA but with $R_{b}>1$ using RA. One watershed with $R_{b}>1$ is identified correctly with WHRA.

\subsection{Effect of Rating Curve Parameter $m$}

For WHRA, the individual recession $b$ values are not preserved from RA, but the value of the $R_{b}$ is not very sensitive to $m$, which makes it a useful metric for this analysis. This section will show how $R_{b}$ is relatively insensitive for a range of $m$ values using examples from the two USGS watersheds and the 37 Swiss watersheds.

Using each individual event for the two USGS watersheds, regardless of the value of $m$ assumed, the values of $b$ for WHRA and RA are positively correlated (Figure 4). Using the water height and discharge data directly, the rating curve with an $m$ is compared to the $b$ values for all individual events for WHRA and RA, showing that the relationship between $b$ values for WHRA and RA using the slope of the regression line does approximate the rating curve exponent $m$. Because all values of $b$ are preserved, the relationship between high and low flow $b$ values is also preserved. Some of the discrepancies between these two values are based on the use of a single rating curve $m$ for the entire period of record when the data suggest some variation in the rating curve though time or a rating curve with a low $R^{2}$ for the power law fit. When $m$ is taken to be 1 , RA is equal to WHRA $b$ values (Figure 4 , red asterisk). For values of $m$ not associated with the rating curve, the scale of $b$ is not preserved but the relationship between the individual recessions is (Figure 4, green open triangles). In addition to the structural decay of flow, the trends in WHRA are also preserved compared to RA trends in $b$ such as seasonality or initial discharge can be analyzed with WHRA as the relationship between values is preserved from RA. Regardless of the value of $m$ assumed, WHRA maintains the linear relationship between individual recession $b$ values and is a valid substitute for $R_{b}$ from RA because the fundamental structural decay of flow is preserved.

For the Swiss watersheds in Figure 3, $m$ is unknown and assumed to be 1 when calculating $R_{b}$ using Equation 10. However, comparing $R_{b}$ using $m=1$ with $R_{b}$ using with the $m$ value from the rating curve (Figure 5), we see that $R_{b}$ is remarkably insensitive to values of $m$. and that assuming $m=1$ still allows us to extract useful information from the stage recession data.
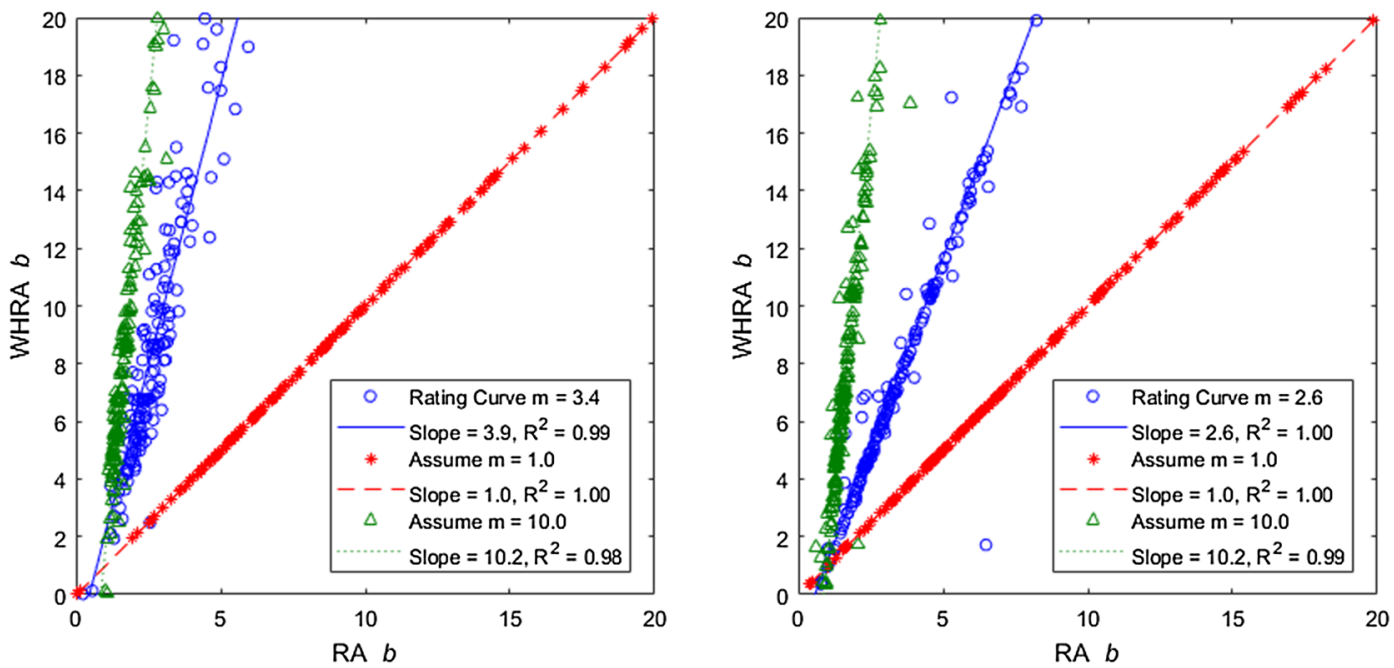

Figure 4. Comparison of individual event $b$ values for RA and WHRA for West Conewago Creek at USGS Station 01574000 (a) and the South Fork of the McKenzie River at USGS Station 14159200 (b). The blue open circles show the data using a rating curve $m$ (3.4 and 2.6, respectively) from the rating curve and the regression line between the RA and WHRA $b$ with a slope of 4.5. For $m=1$ (red asterisk) and $m=10$ (green open triangles), the range of RA $b$ values is different as the scale is not preserved but the relationship between individual recessions is preserved with an $R^{2}$ close to 1 . 


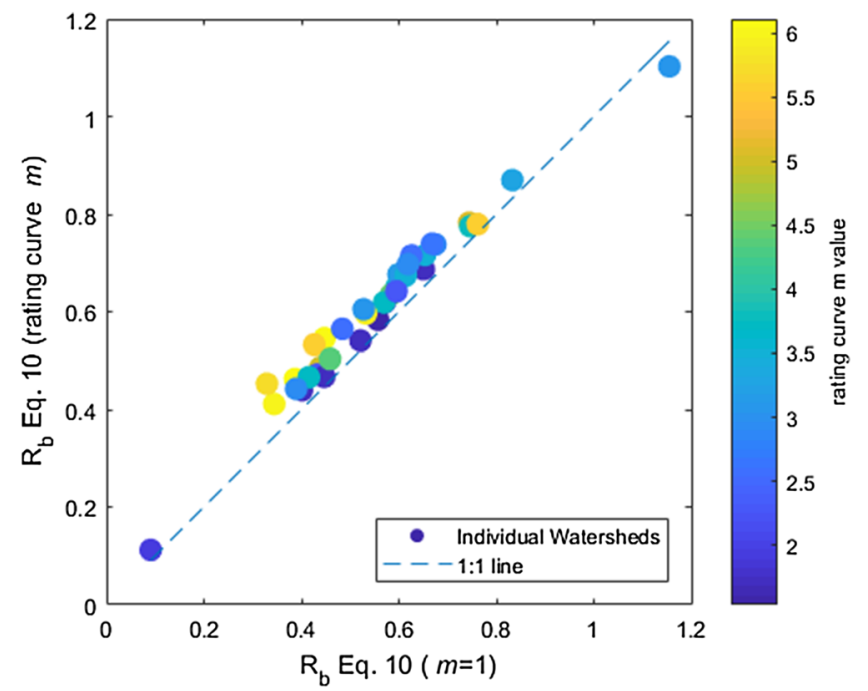

Figure 5. Comparison $R_{b}$ for the assumed $m=1$ versus the $m$ from the rating curve showing that the $R_{b}$ is relatively insensitive to the value of $m$ chosen.
From Figures 4 and 5 we see that see that the relationship between individual $\mathrm{b}$ values is preserved from WHRA $(m=1)$ and RA ( $m$ from the rating curve) regardless of the $m$ value used and that $R_{b}$ is also preserved regardless of the actual value of $m$ for a watershed, and ultimately that $R_{b}$ is insensitive to the value of $m$. For the power law rating curve, we have shown how the WHRA slope $\left(b_{W H R A}\right)$ is a function of the $m$ rating curve exponent. We can quantify the effect of $m$ on WHRA $R_{b}\left(b_{W H R A, h} / b_{W H R A, l}\right)$ by solving Equation 10 for the WHRA $R_{b}\left(b_{W H R A, h} / b_{W H R A, l}\right)$ :

$$
\frac{b_{W H R A, h}}{b_{W H R A, l}}=\frac{m\left(b_{R A, h}-1\right)+1}{m\left(b_{R A l}-1\right)+1}
$$

From Equation 11, RA $R_{b}$ and WHRA $R_{b}$ diverge as $m$ diverges from a value of 1 . Manning's equation plus the assumption that the cross-sectional area is proportional to the water height suggests a value of $m=1.7$, but $m$ can be 2.0 or larger for coarse-grained rivers (e.g., Rupp \& Smart, 2007). For example, if high flow to low flow corresponds with early-time $\left(b_{\mathrm{RA}, \mathrm{h}}=3\right)$ to late-time $\left(b_{\mathrm{RA}, 1}=1.5\right)$ behavior, RA $R_{b}=2$, while WHRA $R_{b}=2.3$ or 2.5 for $m=1.7$ or 2.0 , respectively. These values for $m$ in the 39 watersheds are mostly larger than what would be obtained from Manning's equation, but larger $m$ values could be associated with smaller hydraulic depth in Manning's equation (Smart et al., 2002).

When RA $R_{b}=2$, WHRA $R_{b}$ approaches 4 as $m$ approaches infinity. For the two U.S. watersheds, $m=2.4$ and 2.6 compared to 1.5-6.1 for the Swiss watersheds. The watershed with the smallest $m$ value of 1.5 is Ova da Cluozza, Zernez, Switzerland, and has a WHRA $R_{b}$ of 0.56 based on $b_{W H R A, h}$ and $b_{W H R A, l}$ of 4.7 and 8.4, respectively. For RA, the watershed as an $R_{b}$ of 0.60 based on $b_{W H R A, h}$ and $b_{W H R A, l}$ of 3.6 and 6.0 respectively. Using Equation 11, with $m=2.5$ the resulting WHRA $R_{b}$ is 0.58 and comparable to WHRA $R_{b}$ with the assumed $m=1$. The watershed with the largest $m$ value of 6.1 is Ova da Emme-Emmenmatt, nur Hauptstation, Switzerland, and has a WHRA $R_{b}$ of 0.45 based on $b_{W H R A, h}$ and $b_{W H R A, l}$ of 10.6 and 23.6, respectively. For RA, the watershed as an $R_{b}$ of 0.60 based on $b_{W H R A, h}$ and $b_{W H R A, l}$ of 2.2 and 3.9, respectively. Using Equation 11, with $m=6.1$ the resulting WHRA $R_{b}$ is 0.45 , the same value obtained for WHRA $R_{b}$ with the assumed $m=1$. In Equation 11, while RA $R_{b}$ and WHRA $R_{b}$ diverge as $m$ diverges from a value of 1 , for the same RA $R_{b}$, larger values of $b_{\mathrm{RA}, \mathrm{h}}$ and $b_{\mathrm{RA}, 1}$ will result in WHRA $R_{b}$ approaching the RA $R_{b}$.

\section{Conclusions}

We demonstrate that RA based on water height (stage) can provide insight into transient stream discharge where rating curves are not available. While the magnitude of the actual values of the recession constant $b$ obtained by WHRA is not preserved compared to RA, the magnitude of changes in $b$ as a function in the hydrologic regime are preserved. WHRA generally reproduces the structural decay of flow and $R_{b}$ present in RA with little sensitivity to the assumed rating equation. The structural decay of flow and $R_{b}$ present in WHRA can indicate a transition from high to low flows where the slope of the WHRA plot decreases at lower discharges just as in the RA plot, but the methodology can also identify a break in slope that increases for low discharge. A change in slope is important because it reveals the fundamental flow behavior, signifying a possible boundary condition-driven transition from high to low flows if $R_{b}>1$ or describing a decreased rate of discharge decline for lower flows expressed with a slope ratio less than 1 . With $R_{b}>1$, the sudden increase in slope at low discharge is not consistent with the traditional theory of a constant slope for late time and has been identified but not adequately addressed in the literature (Clark et al., 2009; Mutzner et al., 2013).

Understanding how aquifers drive streamflow during low discharge events is important for streamflow estimation and water management during a hydrologic drought. Preliminary analysis using WHRA can be interpreted based on $R_{b}$ where a break occurs between late-time behaviors or at low discharges. WHRA 
can provide insight into relative watershed characteristics at different flow regimes in basins where dedicated fieldwork for discharge measurements to create rating curves is not feasible.

\section{Data Availability Statement}

The data sets used in this paper are freely available from the USGS website for the watersheds in the United Stated and at http://www.hydroshare.org/resource/58801283d02c4dbcac876bfa86749082 for the watersheds from the Federal Office for the Environment (FOEN), Bern, Switzerland. Respective codes can be obtained from the corresponding author.

\section{Conflict of Interest}

The authors declare that they have no conflict of interest.

\section{References}

Berghuijs, W. R., Hartmann, A., \& Woods, R. A. (2016). Streamflow sensitivity to water storage changes across Europe. Geophysical Research Letters, 43, 1980-1987. https://doi.org/10.1002/2016GL067927

Biswal, B., \& Marani, M. (2014). "Universal” recession curves and their geomorphological interpretation. Advances in Water Resources, 65, 34-42. https://doi.org/10.1016/j.advwatres.2014.01.004

Bogaart, P. W., Rupp, D. E., Selker, J. S., \& van der Velde, Y. (2013). Late-time drainage from a sloping Boussinesq aquifer. Water Resources Research, 49, 7498-7507. https://doi.org/10.1002/2013WR013780

Brutsaert, W., \& Lopez, J. P. (1998). Basin-scale geohydrologic drought flow features of riparian aquifers in the southern Great Plains. Water Resources Research, 34(2), 233-240. https://doi.org/10.1029/97WR03068

Brutsaert, W., \& Nieber, J. L. (1977). Regionalized drought flow hydrographs from a mature glaciated plateau. Water Resources Research, 13(3), 637-643. https://doi.org/10.1029/WR013i003p00637

Clark, M. P., Rupp, D. E., Woods, R. A., Tromp-van Meerveld, H. J., Peters, N. E., \& Freer, J. E. (2009). Consistency between hydrological models and field observations: Linking processes at the hillslope scale to hydrological responses at the watershed scale. Hydrological Processes, 23(2), 311-319. https://doi.org/10.1002/hyp.7154

Clarke, R. T. (1999). Technical note: Uncertainty in the estimation of mean annual flood due to rating-curve indefinition. Journal of Hydrology, 222, 185-190.

Degagnea, M. P. J., Douglas, G. G., Hudson, H. R., \& Simonovic, S. P. (1996). A decision support system for the analysis and use of stage-discharge rating curves. Journal of Hydrology, 184(3-4), 225-241. https://doi.org/10.1016/0022-1694(95)02973-7

Dralle, D., Karst, N., \& Thompson, S. E. (2015). a, b careful: The challenge of scale invariance for comparative analyses in power law models of the streamflow recession. Geophysical Research Letters, 42, 9285-9293. https://doi.org/10.1002/2015GL066007

Dralle, D. N., Karst, N. J., Charalampous, K., Veenstra, A., \& Thompson, S. E. (2017). Event-scale power law recession analysis: Quantifying methodological uncertainty. Hydrology and Earth System Sciences, 21(1), 65-81. https://doi.org/10.5194/hess-21-65-2017

Fenton, J. D., \& Keller, R. J. (2001). The calculation of streamflow from measurements of stage. Cooperative Research Centre for Catchment Hydrology, (report 01/6), 84. Retrieved from http://www.catchment.crc.org.au/pdfs/technical200106.pdf

Federal Office for the Environment (FOEN). (2019). Retrieved from https://www.hydrodaten.admin.ch/en/current-situation-table-discharge-and-water-levels.htmlww.bafu.admin.ch/bafu/en/home.html

Herschy, R. (1993). The stage-discharge relation. Flow Measurement and Instrumentation, 4(1), 11-15. Retrieved from. https://doi.org/ 10.1016/0955-5986(93)90005-4

Jachens, E. R., Rupp, D. E., Roques, C., \& Selker, J. S. (2020). Recession analysis revisited: Impacts of climate on parameter estimation. Hydrology and Earth System Sciences, 24(3), 1159-1170. https://doi.org/10.5194/hess-24-1159-2020

Kennedy, E. J. (1984). Discharge ratings at gaging stations: Techniques of water-resource investigations of the United States Geological Survey. https://doi.org/10.1016/0022-1694(70)90079-X

Kiang, J. E., Gazoorian, C., McMillan, H., Coxon, G., Le Coz, J., Westerberg, I. K., et al. (2018). A comparison of methods for streamflow uncertainty estimation. Water Resources Research, 54, 7149-7176. https://doi.org/10.1029/2018WR022708

Kirchner, J. W. (2009). Catchments as simple dynamical systems: Catchment characterization, rainfall-runoff modeling, and doing hydrology backward. Water Resources Research, 45, W02429. https://doi.org/10.1029/2008WR006912

Lang, M., Pobanz, K., Renard, B., Renouf, E., \& Sauquet, E. (2010). Extrapolation of rating curves by hydraulic modelling, with application to flood frequency analysis. Hydrological Sciences Journal-Journal des Sciences Hydrologiques, 55(6), 883-898. https://doi.org/10.1080/ 02626667.2010 .504186

Lovellford, R. (2013). Variation in the timing of Coho Salmon (Oncorhynchus kisutch) migration and spawning relative to river discharge and temperature. Master of Science Thesis in Water Resources Science at Oregon State University.

McMillan, H. K., Clark, M. P., Bowden, W. B., Duncan, M., \& Woods, R. A. (2011). Hydrological field data from a modeller's perspective: Part 1. Diagnostic tests for model structure. Hydrological Processes, 25(4), 511-522. https://doi.org/10.1002/hyp.7841

Mutzner, R., Bertuzzo, E., Tarolli, P., Weijs, S. V., Nicotina, L., Ceola, S., et al. (2013). Geomorphic signatures on Brutsaert base flow recession analysis. Water Resources Research, 49, 5462-5472. https://doi.org/10.1002/wrcr.20417

Nathanson, M., Kean, J. W., Grabs, T. J., Seibert, J., Laudon, H., \& Lyon, S. W. (2012). Modelling rating curves using remotely sensed LiDAR data. Hydrological Processes, 26(9), 1427-1434. https://doi.org/10.1002/hyp.9225

Phillips, J. C., \& Eaton, B. C. (2009). Detecting the timing of morphologic change using stage-discharge regressions: A case study at Fishtrap Creek, British Columbia, Canada. Canadian Water Resources Journal, 34(3), 285-300. https://doi.org/10.4296/cwrj3403285

Ploum, S. W., Lyon, S. W., Teuling, A. J., Laudon, H., \& van der Velde, Y. (2019). Soil frost effects on streamflow recessions in a sub-arctic catchment. Hydrological Processes, 33(9), 1304-1316. https://doi.org/10.1002/hyp.13401

Reitan, T., \& Petersen-Øverleir, A. (2004). Estimating the discharge rating curve by nonlinear regression - The frequentist approach, (2). Retrieved from http://www.nve.no/Global/Publikasjoner/Publikasjoner\%5Cn2004/Report\%5Cn2004/Trykkefil\%5Cnreport\% 5Cn6-04.pdf 
Reitan, T., \& Petersen-Øverleir, A. (2008). Bayesian power-law regression with a location parameter, with applications for construction of discharge rating curves. Stochastic Environmental Research and Risk Assessment, 22(3), 351-365. https://doi.org/10.1007/s00477-0070119-0

Roques, C., Rupp, D. E., \& Selker, J. S. (2017). Improved streamflow recession parameter estimation with attention to calculation of -dQ/dt. Advances in Water Resources, 108, 29-43. https://doi.org/10.1016/j.advwatres.2017.07.013

Rupp, D. E., \& Selker, J. S. (2006a). Information, artifacts, and noise in dQ/dt - Q recession analysis. Advances in Water Resources, 29(2), 154-160. https://doi.org/10.1016/j.advwatres.2005.03.019

Rupp, D. E., \& Selker, J. S. (2006b). On the use of the Boussinesq equation for interpreting recession hydrographs from sloping aquifers. Water Resources Research, 42, W12421. https://doi.org/10.1029/2006WR005080

Rupp, D. E., \& Smart, G. M. (2007). Comment on "Flow resistance equations without explicit estimation of the resistance coefficient for coarse-grained rivers” by Raul Lopez, Javier Barragan, and M. Angels Colomer. Journal of Hydrology, 346(3-4), 174-178. https://doi.org/ 10.1016/j.jhydrol.2007.08.024

Shaw, S. B., \& Riha, S. J. (2012). Examining individual recession events instead of a data cloud: Using a modified interpretation of $\mathrm{dQ} / \mathrm{dt}$ - Q streamflow recession in glaciated watersheds to better inform models of low flow. Journal of Hydrology, 434-435, 46-54. https://doi.org/10.1016/j.jhydrol.2012.02.034

Smart, G. M., Duncan, M. J., \& Walsh, J. M. (2002). Relatively rough flow resistance equations. Journal of Hydraulic Engineering, 128(6), 568-578. https://doi.org/10.1061/(ASCE)0733-9429(2002)128:6(568)

Tashie, A., Pavelsky, T., \& Band, L. E. (2020). An empirical reevaluation of streamflow recession analysis at the continental scale. Water Resources Research, 56, e2019WR025448. https://doi.org/10.1029/2019WR025448

Tashie, A., Scaife, C. I., \& Band, L. E. (2019). Transpiration and subsurface controls of streamflow recession characteristics. Hydrological Processes, 33(19), 2561-2575. https://doi.org/10.1002/hyp.13530

Troch, P. A., Berne, A., Bogaart, P., Harman, C., Hilberts, A. G. J., Lyon, S. W., et al. (2013). The importance of hydraulic groundwater theory in catchment hydrology: The legacy of Wilfried Brutsaert and Jean-Yves Parlange. Water Resources Research, 49, $5099-5116$. https://doi.org/10.1002/wrcr.20407

U.S. Department of Agriculture-National Resources Conservation Service (USDA-NRCS). (2012). National Engineering Handbook, Part 630, Chapter 14: Stage Discharge Relations. Part 630 Hydrology National Engineering Handbook, (April).

USGS. (2018). WaterWatch: Customized Rating Curve Builder. Retrieved September 10, 2019, from https://waterwatch.usgs.gov/?id=mkrc Wang, D. (2011). On the base flow recession at the Panola Mountain Research Watershed, Georgia, United States. Water Resources Research, 47, W03527. https://doi.org/10.1029/2010WR009910 